\title{
PERANCANGAN APLIKASI MULTIMEDIA BERBASIS COMPUTER BASED TRAINING (CBT) PADA BIDANG TEKNIK VOKASI
}

\author{
Zulkifli $^{1}$ \\ Program Studi Informatika \\ Sekolah Tinggi Teknologi Payakumbuh \\ Email : zulkifli_pyk@yahoo.com
}

\begin{abstract}
Abstrak: Beberapa tujuan penelitian pengembangan model pembelajaran Computer Based Training (CBT) pada bidang vokasi ini adalah pengembangan perangkat pembelajaran dalam bentuk aplikasi multimedia. Sehingga dengan adanya aplikasi mulitmedia CBT ini sebagai perangkat pembelajaran agar siswa dapat mengembangkan pengetahuan dan keterampilannya yang pada gilirannya diharapkan para siswa dapat memperoleh keunggulan kompetitif dan dapat meningkatkan kualitasnya. Penelitian ini merupakan Research \& Development yang terdiri atas beberapa tahapan yaitu: (1) tahap analisis kebutuhan; (2) Desain; (3) Pengembangan; tahap pengembangan terdiri atas tahapan: konsep, perancangan, pengumpulan bahan atau material, pembuatan, testing, dan pengimplementasian. Hasil penelitian pada tahap perancangan dan pengembangan adalah, ditemukan perangkat pembelajaran CBT dalam bentuk aplikasi multimedia menggunakan Perangkat lunak 3Ds Max untuk siswa vokasi sehingga siswa belajar seperti layaknya pratikum namun dengan tampilan dan visualisasi yang menarik serta adanya backsound musik dan suara sehingga tidak membosankan.
\end{abstract}

Kata Kunci: CBT, Aplikasi, Multimedia, kompetitif, 3Ds Max

\begin{abstract}
Several research objectives the development of a model of learning Computer Based Training (CBT) in the field of this device is the development of students learning in the form of multimedia applications. So the existence of this CBT mulitmedia applications as a device of learning so that students can develop the knowledge and skills which in turn expected students can gain a competitive advantage and can increase its quality.

This research is Research Development \& comprising several stages, namely: (1) the needs analysis phase; (2) design; (3) Development; the development phase consists of phases: concept, design, the collection of materials or materials, manufacture, testing, and implementation. The results of the research on the design and development phase is, found the device in the form of CBT learning multimedia applications using the software 3Ds Max for students students so the students learn as training but with display and visualization are interesting as well as the existence of backsound music and sound so it's not boring.
\end{abstract}

Keywords: CBT, applications, Multimedia, competitive, 3Ds Max 


\section{PENDAHULUAN}

\subsection{Latar Belakang}

Proses Belajar Mengajar selain merupakan proses pembelajaran dalam kelas, juga terdapat kegiatan pelatihan atau training yang dilakukan dalam proses belajar mengajar untuk meningkatkan dan mengembangkan pengetahuan serta keterapilan siswa sehingga siswa memiliki keungulan dan kualitas yang mumpuni

Dalam dunia pendidikan, Komputer dapat dimanfaatkan untuk memudahkan proses pencapaian tujuan pendidikan berupa kegiatan pelatihan . Komputer selain dapat dimanfaatkan sebagai alat bantu pembelajaran. Bahkan lebih lanjut, suatu pembelajaran dalam dunia pendidikan dapat dikombinasikan antara metode pembelajaran tatap muka dengan tutorial atau simulasi yang dikenal dengan Computer Based Training (CBT). Pembelajaran berbasis CBT memanfaatkan perangkat keras dan memanfaatkan perangkat lunak Komputer. Perangkat keras berkaitan dengan peralatan pendukung untuk pembelajaran sedangkan Perangkat Lunak berkaitan dengan Multimedia untuk pembelajaran dengan mengunakan 3Ds Max sebagai visualisasi grafik vektor 3 Dimensi dan animasi.

Dalam Pembelajaran Computer Based Training dengan memanfaatkan Multimedia diharapkan memberikan manfaat yang lebih baik dalam proses belajar mengajar, berdasarkan hal ini, penelitian ini sangat penting dilakukan untuk upaya meningkatakan mutu dan kualitas pembelajaran agar menghasilkan lulusan yang memiliki kemampuan dan daya saing yang unggul dan sesuai dengan kebutuhan industri atau pasar kerja.

Permasalahan yang akan dibahas dalam penelitian ini adalah pengembangan model pembelajaran CBT untuk pembelajaran praktek kerja teknik bangunan.

\section{METODE PENELITIAN}

\subsection{Jenis Penelitian}

Penelitian ini menggunakan pendekatan Research and Development yang dikembangkanoleh Borg and Gall (1983) yang dimodifikasi menjadi 5, yang dapat dilihat seperti pada Gambar 1.

\subsection{Variabel Penelitian}

Variabel penelitian adalah segala sesuatu yang akan menjadi objek pengamatan dalam penelitian. Sesuai permasalahan yang di teliti, maka variabel penelitian meliputi data-data Profil Kompetensi.

\subsection{Langkah-langkah Penelitian}

Dalam Penelitian ini dapat diuraikan tahapan penilitian seperti gamabar 1 berikut:

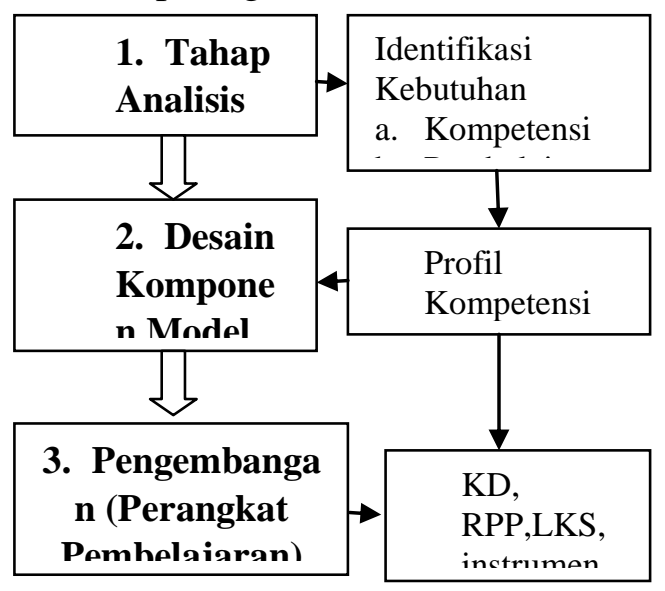

Gambar 1 Tahapan Penelitian

Tahap penelitian adalah,

1. Tahap Analisis Kebutuhan, kegiatan pada tahap ini adalah:

a) Mengidentifikasi kompetensi kebutuhan DUDI.

b) Identifikasi kebutuhan pembelajaran di sekolah.

2. Tahap Desain, merancang komponen model, dengan menyusun matriks kompetensi dan profil Kompetensi Dasar.

3. Tahap pengembangan komponen model, kegiatan pada tahap ini adalah mengembangkan Model pembelajaran. yang terdiri dari: konsep, perancangan, pengumpulan bahan atau material, 
pembuatan, testing,

dan pengimplementasian.

\section{HASIL DAN PEMBAHASAN}

Hasil penelitian untuk tahap analisis kebutuhan, pertama adalah melaksanakan workshop, melibatkan pihak para ahli (expert worker) sebagai sumber informasi kompetensi yang dibutuhkan bidang kerja teknik bangunan. sehingga menghasilkan inventarisasi kompetensi kerja yang dijadikan kerangka kompetensi dasar (KD) sesuai kebutuhan situasi kerja yang nyata. Setelah kerangka KD ditemukan, maka diadakan diskusi dengan guru-guru atau dosen-dosen untuk mengidentifikasi kompetensi lebih terfokus sesuai kata kerja operasional, yang menjadi draf profil kompetensi, sesuai kebutuhan pembelajaran di sekolah.

Kompetensi kerja yang terinventarisasi kemudian dianalisis sesuai cakupan materi lebih terfokus sesuai kata kerja operasional. Dari hasil kegiatan tahapan analisis kebutuhan, dirumuskan profil kompetensi dasar, yang dijadikan acuan untuk mengembangkan komponen model pembelajaran CBT Teknik Bangunan.

\subsection{Pembuatan Multimedia}

Dalam pembuatan Multimedia dalam pengembangan aplikasi dilakukanlah tahapantahapan berikut: Tahapan pengkonsepan, melakukan perancangan, pengumpulan bahan atau material, pembuatan aplikasi, testing, dan pengimplementasian.

\section{Konsep (Concept)}

Pembuatan rancangan materi pelatihan dengan aplikasi multimedia ini akan digunakan sebagai media penyampaian informasi tentang tahapan-tahapan dalam proses pembuatan rumah sederhana bagi siswa Teknik Bangunan. Sedangkan fitur multimedia yang telibat disini ada berupa: Teks dan Gambar serta audio dan video dalam bentuk animasi sehingga memudahkan siswa dalam proses belajar mengajar serta menarik bagi siswa dalam proses pelatihan.

\section{Membuat Rancangan}

Dalam membuat rancangan ini dilakukan beberapa rancangan yaitunya: membuat rancangan alur tahapan kegiatan pembangunan, kemudian melakukan perancangan peralihan tampilan multimedia dari satu kondisi ke kondisi berikutnya kemudian dilakukan perancangan tampilan atau layout multimedianya sebagai user interface.

\section{Pembuatan (Assembly)}

Dalam pembuatan Aplikasi Multimedia computer based training ini dibutuhkan spesifikasi perangkat keras dan perangkat lunak, sebagai berikut:

a. Komputer yang dipergunakan dalam pembuatan aplikasi ini dibutuhkan Komputer dengan Prosessor Core i5 agar memberikan kinerja yang maksimal sehingga tidak lambat dalam menampilkan image yang bagus.

b. Perangkat lunak yang dipergunakan yaitu software 3Ds Max 2004 untuk membuat aplikasi multimedia dengan tampilan yang interaktif.

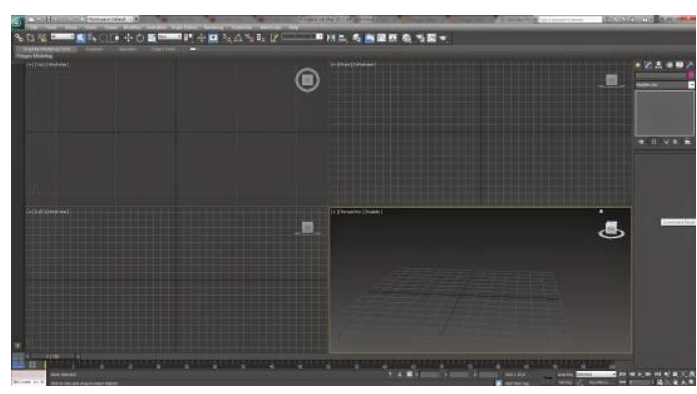

Gambar 2. Layout Program 3Ds Max

c. Adobe Photoshop CS untuk mendesain background tampilan.

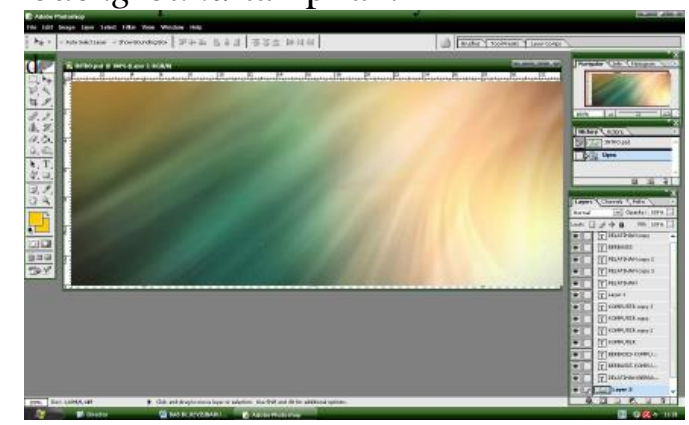

Gambar 3. Layout Program Adobe Photoshop CS 
Setelah software atau perangkat lunak tersedia kemudian dilakukan tahap berikutnya yaitu membuat aplikasi multimedia dengan mengunakan 3Ds Max 2004 yang suadah disiapkan sebelumnya.

\section{Pengujian}

Selanjutnya dilakukan pengujian terhadap aplikasi multimedia yang sudah dibangun, apakah sudah bisa berjalan sesuai dengan harapan dan keinginan apa belum, setelah itu dilakukan mengujian kembali pada komputer lain, apakah aplikasi yang sudah dibangun juga bisa dijalankan pada komputer yang berbeda.

\section{Penerapan atau Pengimplementasian}

Dalam pengimplementasian aplikasi ini dilakukan dengan cara mencobakan ke siswa apakah aplikasi ini dapat membantu dalam proses belajar mengajar bagi siswa terutama dalam kegiatan pelatihan sehingga mahasiswa jadi lebih mandiri.

\section{IMPLEMENTASI SISTEM}

Beberapa tahap implementasi dan evaluasi yang dilakukan:

\section{Tampilan Aplikasi}

Pada tahapan ini siswa dapat melihat dan memahami tahapan memancang ruangruang yang akan dibangun dan dibuat seperti gambar 4 .

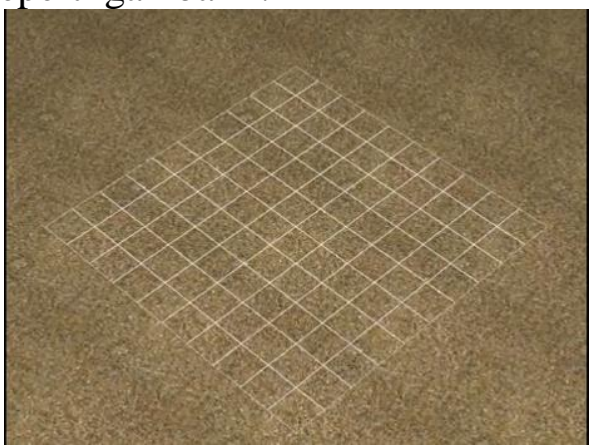

Gambar 4. Tahapan Memancang

Setelah tahapan pemancangan dilanjutkan pengalian pondasi seperti pada gambar 5 .

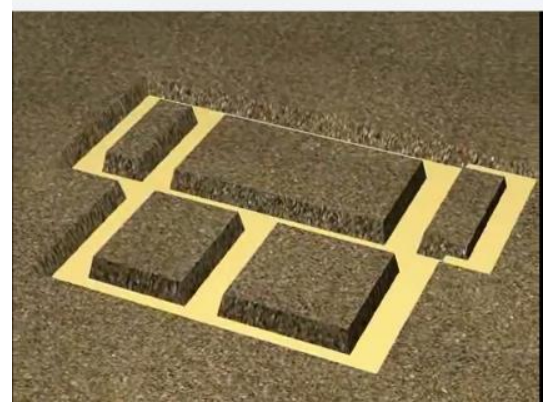

Gambar 5 Tahapan pengalian pondasi

Setelah tahapan pembuatan pondasi rumah selesai dikerjakan, berikutnya dilanjutkan pada tahapan pembuatan pondasi bangunan yang dapat dilihat pada gambar 6 .

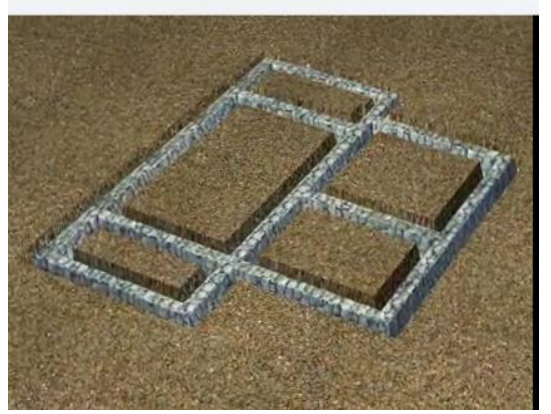

Gambar 6 Tahapan pembuatan Pondasi

Setelah pondasi selesai dikerjakan kemudian dilanjutkan dengan pemasangan slope dan dilanjutkan pemasangan batu bata, dan plesteran dapat dilihat pada gambar 7 .

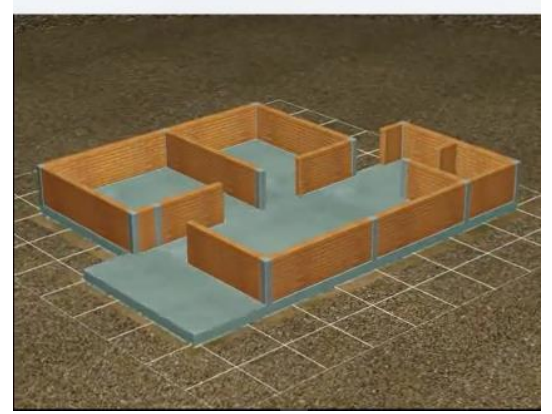

Gambar 7 Tahapan pemasangan slope dan batu bata

Tahapan berikutnya setelah pegerjaan slope dan pemasangan batu bata selesai dikerjakan dilanjutkan dengan pamasangan konsenkonsen yang diperlukan baik itu konsen jendela maupun konsen pintu. Tahapan ini dapat dilihat pada gambar 8 . 


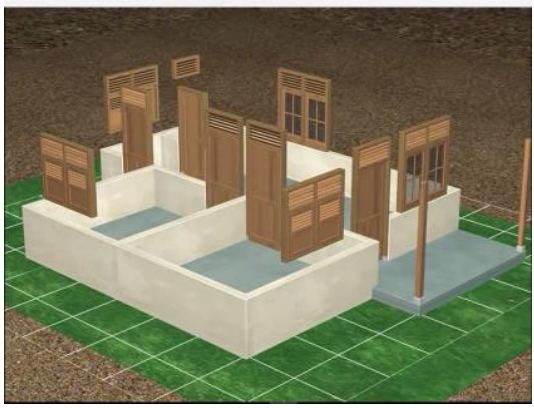

Gambar 8 Tahapan pemasangan konsen

Selesai pengerjaan pemasangan konsen tahapan berikutnya dilanjutkan dengan pemsangan tiang-tiang baik itu tiang utama bangunan maupun tiang untuk pemasangan papan yang dapat dilihat pada gambar 9 .

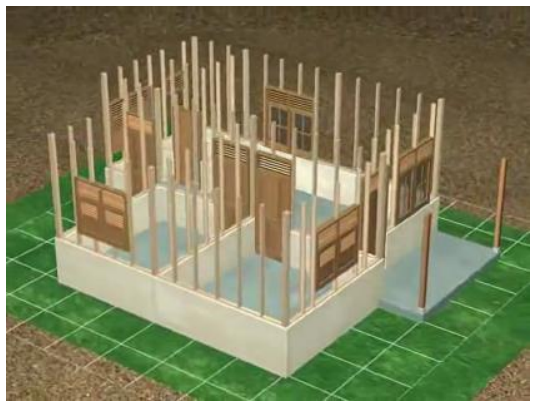

Gambar 9 Tahapan pemasangan tiang

Berikutnya dilanjutkan dengan tahapan pemasangan kuda-kuda bangunan seperti yang dapat dilihat pada gambar 10 .

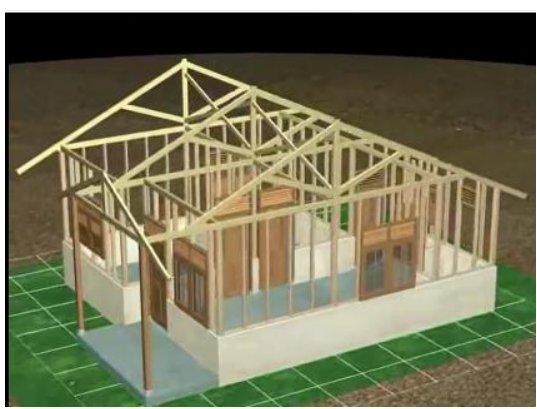

Gambar 10 Tahapan pemasangan kuda-kuda

Setelah selesai pemasangan kuda-kuda rumah berikutnya dilanjutkan dengan tahapan pemasangan dudukan atap rumah berupa pemasangan kayu ukuran kayu 5 x $10 \mathrm{~cm}$ secara horizontal yang dapat dilihat pada gambar 11.

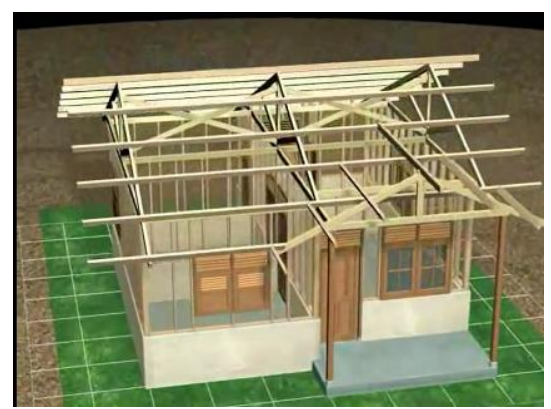

Gambar 11. Tahapan Pemasangan dudukan atap

Pada tahapan berikutnya setelah pengerjaan dudukan atap selesai dikerjakan adalah pemasangan atap dan pemasangan papan untuk dinding rumah yang dapat dilihat seperti gambar 12 berikut.

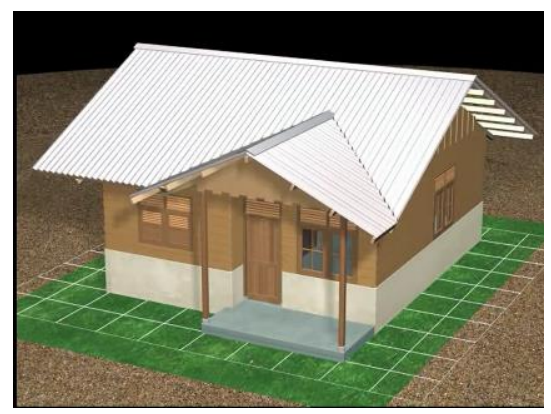

Gambar 12 Tahapan Pemasangan dinding dan atap

Setelah pemasangan atap dan pemasangan dinding papan selesai dikerjakan berikutnya adalah malakukan finising bangunan apakah itu coran lantai, pemasangan acian dan lesplang dapat dilhat pada gambar 13.

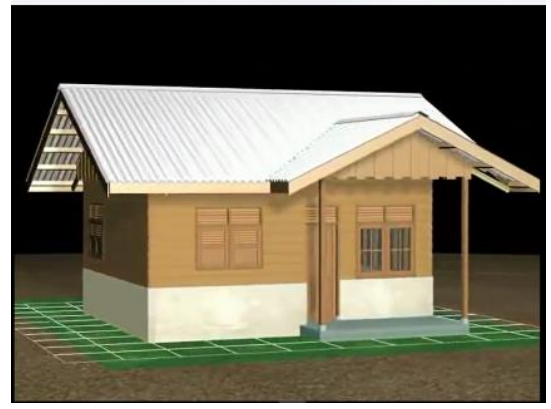

Gambar 13 Tahapan finishing

\section{Pengoperasian Program}

Aplikasi ini dapat dioperasikan secara manual dan secara otomatis, pengoperasian secara otamatis adalah pengoperasian yang dilakukan oleh komputer secara autorun sehingga aplikasi langsung running diwaktu 
software dihubungkan ke drive yang ada pada komputer.

\section{Penilaian Program atau evaluasi Aplikasi}

Setelah dicobakan penerapan aplikasi multimedianya kemudian baru dapat dilakukan penilaian atau evaluasi dari aplikasi yang sudah dicobakan tadi.

\section{KESIMPULAN}

Berdasarkan hasil penelitian yang telah dilaksanakan, dapat diambil beberapa kesimpulan seperti berikut:

1. Menghasilkan Model Computer Based Test (CBT) Berbasis 3Ds Max untuk siswa vokasi

2. Computer Based Test (CBT) ini dapat dijadikan sebagai referensi pendukung pembelajaran teknik bangunan

3. Pembuatan Computer Based Test (CBT) ini menggunakan alur pengajaran yang bersifat tutorial sehingga siswa belajar seperti layaknya pratikum namun dengan tampilan dan visualisasi yang menarik serta adanya backsound musik dan suara sehingga tidak membosankan

4. Hasil model computer based test (CBT) berbasis piranti lunak 3Ds Max untuk siswa vokasi adalah valid;

5. Hasil model computer based test (CBT) berbasis piranti lunak 3Ds Max untuk siswa vokasi adalah praktis

6. Hasil model computer based test (CBT) berbasis piranti lunak 3Ds Max untuk siswa vokasi adalah efektif

\section{DAFTAR PUSTAKA}

Borg and Gall. (1983). Educational Research: An Introduction. Fourth Ed. New York: Longman Inc.

Dhabith Shabrina Yandari Putri (2016). Pembelajaran dengan pendekatan Competency based training (cbt) di lkp belva Di desa sidorejo, kecamatan karangawen, Kabupaten demak. Semarang. Universitas negeri semarang

Katong DS (2010). Belajar Animasi Rumah Sederhana.https://id.savefrom.net/\#url=ht
tp://youtube.com/watch?v=7R-0Jqb-

EnM\&utm_source=youtube.com\&utm_m edium=short_domains\&utm_campaign= www.ssyoutube.com

Lia amalia, Suwatno(2016). Peningkatan Kompetensi Siswa Melalui Efektivitas Competency Based Training. Jurnal Pendidikan Manajemen Perkantoran Volume 1, Nomor 1, Agustus 2016

Luther, A. C., 1994, Authoring Interactive Multimedia, Academic Press, Inc., Massachusettes.

Mimi Miftahul Jannah (2010). Aplikasi Multimedia Computer Based Training (CBT) Untuk Bantuan Operasional Sekolah Pada Kantor Depag Kabupaten Tangerang. Jakarta. Universitas islam negeri syarif hidayatullah

Riana T. Mangesa (2016). Pengembangan Perangkat Pembelajaran Competence Based Training (CBT) Berbasis Kompetensi Kerja Di Sekolah Menengah Kejuruan (SMK). Jurnal mekom, vol.3 no. 2 agustus 2016.

Sulistria, hafidudin, makfi (2007). Perancangan dan Pembuatan CBT (computer base Training) Untuk Teknologi Softswitch (Design And Implementation Of CBT(computer base Training) For Softswitch Technology). Bandung. Universitas telkom

Sunarso dan Paryanto (2014). Model Pembelajaran Competence Based Training (CBT) Berbasis Karakter Untuk Pembelajaran Praktik Kerja Mesin Di sekolah menengah kejuruan. Jurnal pendidikan karakter, tahun iv, nomor 3, oktober 2014

Sutopo, A. H., (2003), Multimedia Interaktif dengan Flash, Graha Ilmu, Yogyakarta.

Yohanes Adio Balan, Sudarmin \& Kustiono(2017). Pengembangan Model Computer Based Test (CBT) Berbasis Adobe Flash untuk Sekolah Menengah 
Kejuruan. Innovative Journal of Curriculum and Educational Technology IJCET 6 (1) (2017) 